\title{
Imaging the hydrated microbe-metal interface using nanoscale spectrum imaging
}

DOI:

10.1002/ppsc.201600073

\section{Document Version}

Accepted author manuscript

Link to publication record in Manchester Research Explorer

\section{Citation for published version (APA):}

Lewis, E., Haigh, S., Downie, H., Collins, R., Prestat, E., \& Lloyd, J. (2016). Imaging the hydrated microbe-metal interface using nanoscale spectrum imaging. Particle and Particle Systems Characterization.

https://doi.org/10.1002/ppsc.201600073

\section{Published in:}

Particle and Particle Systems Characterization

\section{Citing this paper}

Please note that where the full-text provided on Manchester Research Explorer is the Author Accepted Manuscript or Proof version this may differ from the final Published version. If citing, it is advised that you check and use the publisher's definitive version.

\section{General rights}

Copyright and moral rights for the publications made accessible in the Research Explorer are retained by the authors and/or other copyright owners and it is a condition of accessing publications that users recognise and abide by the legal requirements associated with these rights.

\section{Takedown policy}

If you believe that this document breaches copyright please refer to the University of Manchester's Takedown Procedures [http://man.ac.uk/04Y6Bo] or contact uml.scholarlycommunications@manchester.ac.uk providing relevant details, so we can investigate your claim.

\section{OPEN ACCESS}




\section{Imaging the hydrated microbe-metal interface using nanoscale spectrum imaging}

Edward A. Lewis, Helen Downie, Richard F. Collins, Eric Prestat, Jonathan R. Lloyd", Sarah J. Haigh ${ }^{*}$

E. A. Lewis, Dr. E. Prestat, Dr S. J. Haigh

School of Materials, University of Manchester, M13 9PL, UK

Dr. H. Downie, Prof. J. R. Lloyd

School of Earth, Atmospheric and Environmental Sciences, University of Manchester, M13

9PL, UK

Dr. R. F. Collins

Faculty of Life Sciences, University of Manchester, M13 9PT, UK

E-mail:

Keywords: liquid-cell, in situ, Geobacter, bimetallic, nanocrystal

PdAu nanocrystals were synthesised by Geobacter sulfurreducens, a dissimilatory metalreducing bacterium, and the resulting bimetallic nanocrystal decorated microbes were imaged using a range of advanced electron microscopy techniques. Specifically we report the first example of elemental mapping of fully hydrated biological nanostructures using scanning transmission electron microscope (STEM) energy dispersive X-ray (EDX) spectrum imaging within an environmental liquid-cell. We combine these results with cryo-TEM and ex situ STEM imaging and EDX analysis with the aim of better understanding microbial synthesis of bimetallic nanoparticles. We demonstrate that although Au and Pd are colocalised across the cells, the population of nanoparticles produced is bimodal, containing ultra-small alloyed nanocrystals with diameters $<3 \mathrm{~nm}$ and significantly larger core-shell structures (> 200nm in diameter) which show higher Pd contents and exhibited a Pd enriched rich shell only a few nanometres thick. The application of high-resolution imaging techniques described here offers the potential to visualise the microbe-metal interface during the bioproduction of a range of functional materials by microbial "green" synthesis routes, and also key interfaces underpinning globally relevant environmental processes (e.g. metal cycling). 


\section{Introduction}

The nanoscale interface between microbial cells and inorganic structures has a huge impact on natural and engineered systems. Bacterial reduction of metals is of interest both for the recovery of metals from wastewater and for the synthesis of functional nanomaterials. ${ }^{[1]}$ Due to the mild reaction conditions and absence of costly or toxic reagents, biological synthesis of nanomaterials is a safe, economical, scalable, and environmentally friendly alternative to more commonly employed chemical routes. ${ }^{[1]}$ Bacteria have been employed to synthesise a range of metallic and semiconducting nanocrystals, ${ }^{[2]}$ utilising their inherent abilities to transfer electrons to redox active metals. ${ }^{[3]}$ Geobacter sulfurreducens, a metal-reducing subsurface proteobacterium, has been used to synthesise a range of functional nanomaterials, including $\mathrm{Pd}$ and $\mathrm{Ag}$ nanoparticles, and $\mathrm{Pd}$ nanoparticle decorated magnetite $\left(\mathrm{Fe}_{3} \mathrm{O}_{4}\right) .{ }^{[2 \mathrm{~b}, 4]}$ Recent work on the biosynthesis of magnetite nanoparticles by this organism has shown that such systems are both highly tunable, with respect to particle size, reactivity and magnetic properties, and are amenable to industrial scale-up. ${ }^{[5]}$ These results are particularly significant as a lack of morphological control is a common challenge for nanomaterials produced via bacterial synthesis routes, often resulting in highly polydisperse nanocrystal populations. ${ }^{[4 a, 6]}$ Production of bimetallic, alloyed or core-shell nanocrystals is important as such particles often display superior properties to their monometallic counterparts. ${ }^{[7]}$ For such systems, the spatial distribution of two elements within a nanocrystal can dramatically influence the catalytic performance, so controlling elemental distributions is highly desirable. ${ }^{[8]}$ More specifically, PdAu nanoparticle systems have attracted a large amount of interest, outperforming monometallic $\mathrm{Pd}$ in a wide range of catalytic reactions. ${ }^{[9]}$ A number of examples of the bacterial synthesis of PdAu nanoparticles have been reported. ${ }^{[2 c, 6,10]}$ For example, co-precipitation of Au and Pd by Shewanella oneidensis has been used to synthesise 
Bio-PdAu which has successfully been used to catalyse the dechlorination of pollutants and the Suzuki coupling reaction. ${ }^{[6,10 a]}$ However, the catalytic activities of these bio-synthesised PdAu structures are currently 1000 times poorer than chemically synthesised Au-core Pdshell particles, ${ }^{[6,9 c]}$ and it has been suggested that the lack of control over elemental segregation in Bio-PdAu may be partly responsible for its sub-optimal performance. ${ }^{[6]}$ It is increasingly recognised that a greater level of control will need to be achieved if bacterial synthesis methods are to realise their potential as scalable, environmentally sustainable routes for producing nanomaterials. ${ }^{[1 \mathrm{a}, 11]}$ Achieving this goal is likely to require an improved mechanistic understanding of bacterial nanocrystal growth. Specifically improved characterisation of electron transfer pathways at the nanoparticle/cellular membrane interface during biological manipulations (e.g. using the emerging tools of synthetic biology) will help fine-tune such biotechnological systems, while delivering improved understanding of a range of natural processes. ${ }^{[12]}$ Similarly, precise understanding of the resulting nanocrystals' structures, including the nanoscale distribution of elements in bimetallic nanocrystals, will be necessary for building rigorous structure-property relationships and optimising catalytic performance. $^{[8,13]}$

Here we have investigated the microbial synthesis of metal nanoparticles using STEM imaging and a modified 'liquid-cell' environmental specimen holder. ${ }^{[14]}$ This allows hydrated specimens and solution phase processes to be imaged in real-time with nanometre resolution. ${ }^{[14 \mathrm{~b}, 14 \mathrm{c}]}$ This emerging technique has allowed direct observation of the growth and dynamic motion of nanocrystals in solution. ${ }^{[15]}$ Similar liquid-cell holders have previously been applied to image a variety of biological structures in their native hydrated state. ${ }^{[16]}$ The technique has been used to study protein distributions in mammalian fibroblast cells, where it can surpass fluorescence microscopy in terms of both resolution and speed, ${ }^{[16 a]}$ and to observe uptake of nanoparticles by glioblastoma stem cells. ${ }^{[17]}$ Whilst the majority of such 
studies have focused on imaging eukaryotic cells, ${ }^{[16 a, 18]}$ bacterial cells have also been investigated. ${ }^{[19]}$ Of particular relevance to this work is a recent liquid-cell study of magnetosome membrane integrity in magnetotactic bacteria. ${ }^{[19 b]}$ In contrast to previous liquid-cell studies where the contrast for high angle annular dark field (HAADF) STEM imaging is improved by incubation with high atomic number nanocrystals, ${ }^{[16 c, 17,18 b, 19 a]}$ the biomineralized magnetite within magnetosomes produced by magnetotactic bacteria serve as natural high-contrast labels. ${ }^{[19 b]}$

Most (S)TEM liquid-cells are incompatible with complementary spectroscopic characterisation techniques: electron energy loss spectroscopy (EELS); and EDX spectroscopy. EELS is achievable in some thin liquid-cells, ${ }^{[20]}$ however, the size of whole biological-cells ( >500 nm) prevent EELS being used effectively for such thick specimens. A different hurdle usually limits EDX spectroscopy during liquid-cell experiments; here the sides of the liquid-cell holder prevent the X-ray signals from reaching the EDX detector(s) resulting in poor X-ray collection efficiencies. In this study we apply a modified holder design to overcome this problem, ${ }^{[21]}$ facilitating for the first time EDX elemental mapping of hydrated microbial structures. This new approach has the potential to provide valuable insights into processes at the biological-inorganic interface such as during biological synthesis of nanomaterials, where the chemical composition of biodeposited species may show temporal and spatial variations on both the cellular level, and within individual nanostructures. ${ }^{[2 \mathrm{c}, 6]}$

\section{Results and Discussion}

Washed cells of Geobacter sulfurreducens were used to synthesise $\mathrm{Pd}, \mathrm{Au}$, and $\mathrm{PdAu}$ nanoparticles, forming nanocrystal decorated bacteria. Control experiments confirmed that Geobacter sulfurreducens was able to reduce both $\mathrm{Au}(\mathrm{III})$ and $\mathrm{Pd}(\mathrm{II})$ independently, using $\mathrm{H}_{2}$ 
as an electron donor. The resulting bio-inorganic nanocomposite materials are referred to as Bio-Au, Bio-Pd, and Bio-PdAu. We were able to successfully load a Bio-PdAu suspension into a liquid-cell specimen holder with ultra-thin silicon nitride windows, and thus study the hydrated structure using HAADF STEM imaging and EDX spectrum imaging. This is the first demonstration of EDX analysis of a biological specimen in a liquid-cell.

The fact that the structures observed were in a hydrated environment was confirmed by the extent of motion seen both for isolated nanoparticles and for whole bacterial cells under the action of the electron beam (see SI video 1). In addition the EDX signal shows a high O/Si ratio $\left(\mathrm{O}_{\mathrm{k}} / \mathrm{Si}_{\mathrm{k}}\right.$ typically $>1$; SI Figure $\left.\mathrm{S} 1\right)$, which has been shown previously to indicate a thick aqueous liquid layer between the $\mathrm{SiN}_{\mathrm{x}}$ windows. ${ }^{[21 \mathrm{a}]}$ We note that the liquid-cell thickness varies dramatically across the viewing area due to window bowing, ${ }^{[20 a]}$ and consequently we observed that the best contrast and resolution could be achieved on structures located near the window's edge.

Ellipsoid shaped structures, of a size $(\sim 1 \mu \mathrm{m}$ in length) and shape consistent with whole cells of Geobacter sulfurreducens were commonly seen inside the liquid-cell (Figure 1), with the bacteria showing a tendency to aggregate. Due to the strong dependence of HAADF imaging on atomic number, the metal nanocrystals appear far brighter than the biological material, making visual identification of the nanocrystals straightforward. Indeed, we were able to resolve individual nanocrystals less than $15 \mathrm{~nm}$ in diameter (SI Figure S2). The strong contrast of dense, high atomic number nanocrystals compared to low atomic number biological material in HAADF images has been exploited previously in liquid-cell studies. ${ }^{[16 \text {, }}$ ${ }^{18 b]}$ However, in such cases the nanocrystals were intentionally introduced into the cell, either as a label (for example labelling of mammalian fibroblast cells with Au nanoparticles, ${ }^{[16 a]}$ or $\mathrm{CdSe} / \mathrm{CdZnS}$ quantum dots, ${ }^{[16 c]}$ and labelling of $E$. coli bacteria with gold nanoparticles ${ }^{[19 \mathrm{a}]}$ ) or to study nanocrystal uptake (in the case of Au nanoparticle uptake by fibroblast ${ }^{[18 b]}$ and 
glioblastoma cells $\left.{ }^{[17]}\right)$. In contrast, the nanocrystals observed in this work were synthesised by the bacterium Geobacter sulfurreducens. The magnetotactic bacterium Magnetospirillum magneticum has been imaged previously using liquid-cell STEM, while these bacteria also synthesise nanocrystals, they produce intracellular chains of highly uniform magnetite nanocrystals. ${ }^{[19 b]}$ In contrast, the bacteria studied in this work produce polydisperse extracellular or membrane-bound PdAu nanocrystals of unknown composition and elemental distribution.

Cells with high nanocrystal coverage were clearly brighter around their perimeter; suggesting that the nanocrystals are primarily located on the surface of the cell. HAADF STEM imaging also allowed the degree of nanocrystal coverage of individual cells to be assessed and this varied considerably across the samples. Some cells appeared very bright, being decorated with hundreds of individual nanocrystals that could be clearly resolved, others had comparatively low nanocrystal loading or did not show any evidence of nanocrystals. Highly loaded and bare cells were found to coexist in the same aggregates and displayed no obvious differences in size and shape. However, we note that, despite their low atomic number, the bare microbes were still visible in HAADF STEM images (Figure 1b). Similar inhomogeneity can be seen in previous reports of Pd nanoparticle synthesis using cells of Geobacter, ${ }^{[4 \mathrm{a}]}$ and most likely reflects the inherent physiological heterogeneity within the late exponential cultures that were washed and used in these experiments.

The Bio-PdAu suspensions also contained free nanostructures in addition to the decorated bacteria. Chains and small aggregates of nanocrystals were seen emanating from bacterial cells and floating freely in solution. These nanocrystals could be formed by extracellular structures produced by the bacteria, such as pili which are thought to be involved in transferring electrons from bacteria to insoluble electron acceptors. ${ }^{[3 \mathrm{a}]}$ The unbound nanostructures could highlight pili sheared from cell surfaces or may be nanocrystals bound 
together by extracellular polymeric substances (EPS), potentially containing metal-reducing cytochromes. $^{[22]}$

Our observations of the morphology of cells and nanocrystals, as well as the location of the Bio-PdAu nanocrystals on the microbe's surface are consistent for both in situ liquid-cell HAADF STEM imaging and cryo-TEM imaging (Figure 2). The surface localisation of nanocrystals is also consistent with previous work identifying $c$-type cytochromes located in the outer membrane as playing a key role in the reduction of metals by Geobacter cells. ${ }^{[23]} \mathrm{A}$ previous study of Pd reduction by Geobacter cells showed very few nanocrystals inside living cells. ${ }^{[4 \mathrm{a}]}$ However, when the cells were killed intracellular Pd nanocrystals were observed, most likely due to membrane rupture. ${ }^{[4 a]}$ It seems probable that the surface localisation of nanocrystals observed in the present study arises due to a combination of ctype cytochromes, located on the surface of Geobacter cells, being responsible for electron transfer, ${ }^{[3 b]}$ and the cell membrane inhibiting nanocrystals from entering the cells. ${ }^{[4 a]}$ However, it should be noted that intracellular nanocrystals are observed in other bacterial systems, for example, Pd reduction by Enterococcus faecalis results in Pd nanocrystal formation both at the membrane and internally. ${ }^{[24]}$ HAADF imaging contrast can easily differentiate between biological structures and metal nanocrystals, but determining elemental compositions from HAADF images alone is challenging or impossible. It is conceivable that only one of the two metals could have been reduced by the bacteria, or that the reduction processes could be spatially inhomogeneous with distinct regions of $\mathrm{Au}$ nanocrystals and regions of Pd nanocrystals. Unique to this work, we have obtained EDX spectra (Figure 1d) and spectrum images (Figure 3) of the fully hydrated structures in the liquid-cell, ${ }^{[21]}$ in order to study the elemental distributions within the bio PdAu. EDX spectrum images of Bio-PdAu structures demonstrated co-localisation of 
the $\mathrm{Au}$ and $\mathrm{Pd} \mathrm{X}$-ray signals, supporting the theory that cells are decorated with $\mathrm{PdAu}$ nanocrystals (Figure 3 and SI Figure 1).

Encouragingly no cell lysis was seen, even under prolonged imaging (times of over 100s and fluences of over $10^{10}$ electrons). However, beam induced motion was a problem when attempting to acquire high quality EDX spectrum images using long acquisition times. It is well known that the electron beam can induce both the growth and motion of nanostructures in liquid-cell experiments. ${ }^{[15 b, 25]}$ While we observed no metal nanocrystal growth (indicating that no residual $\mathrm{Au}(\mathrm{III})$ or $\mathrm{Pd}(\mathrm{II})$ were present in solution $),{ }^{[26]} \mathrm{Bio}-\mathrm{PdAu}$ structures were observed to undergo a number of morphological transformations during imaging.

Translational and rotational motion, and shrinkage of the bacteria were all observed (SI video 1). These observations are consistent with the work of Woehl et. al., who found that bacteria are not lysed during liquid-cell STEM imaging, but that imaging can induce contractions attributed to radiolysis of the cytoplasm. ${ }^{[19 \mathrm{~b}]}$ Such beam damage poses a problem if we wish to perform high quality spectrum imaging of biologically synthesised nanostructures in their native state, as the structure of interest must remain stationary and structurally unchanged for a period of time sufficient to acquire a significant number of X-ray counts (typically over 100 seconds at moderate beam current of $100 \mathrm{pA}$ ).

We monitored the size and position of individual cells as a function of electron dose (Figure 4). The cells initially underwent some shrinkage and rotation relative to one another (through $\sim 40^{\circ}$ ), but, as the total electron dose increased these dynamic processes slowed and eventually ceased. The structures ultimately reached a stable state (after a local dose of $\sim 7.5 \times 10^{9} \mathrm{e}^{-}$) where dynamic changes were minimal, and thus spectrum imaging was feasible. EDX spectrum imaging of hydrated Bio-PdAu in this stable state was able to resolve elemental segregation in a large PdAu nanostructure with a diameter of $200 \mathrm{~nm}$ (Figure 4c and d) 
The time and electron dose required to acquire a single STEM image is orders of magnitude lower than that required to collect sufficient X-ray counts to form a spectrum image of the same structure. Consequently, the rate of beam-induced motion encountered has little effect on HAADF imaging but is the major factor limiting resolution in EDX spectrum images. The PdAu nanocrystals did not appear to be damaged by the electron beam, and their size and shape were unchanged by irradiation (Figure 4b); their motion was a consequence of being anchored to the shrinking and rotating microbial cell. Flourescence microscopy has been used previously to investigate the viability of cells before and after imaging. ${ }^{[18 \mathrm{~d}, 19 \mathrm{~b}]}$ While yeast cells are deemed not to be viable after STEM imaging, ${ }^{[18 \mathrm{~d}]}$ post STEM fluorescence imaging of magnetotactic bacteria show that the cell wall membrane is not damaged, although cell viability is challenging to assess. ${ }^{[19 \mathrm{~b}]}$ De Jonge and co-workers suggest that the initial STEM image in a liquid-cell experiment can accurately capture the structure of live mammalian fibroblast cells. ${ }^{[18 \mathrm{~b}]}$ We therefore propose an acquisition procedure where an initial HAADF image is recorded providing an accurate high resolution record of the authentic hydrated structure, showing the cellular location of individual nanocrystals. ${ }^{[18 b]}$ The structure is then irradiated with the electron beam until it has reached a stable state, the nanocrystals can then be analysed by EDX spectroscopy and this information correlated back to the structure revealed in the original HAADF image.

A number of strategies for mitigating beam damage can be envisioned for future studies. ${ }^{\text {[27] }}$ Further improvements in detector design could lead to improved temporal resolution and lower electron doses. This is true both for TEM imaging, where direct electron detectors are already allowing extremely high frame-rate imaging of nanocrystals in liquid-cells, ${ }^{[28]}$ and with STEM EDX analysis, where increasing collection solid angles will result in more X-ray counts for a given electron dose. ${ }^{[2]}$ In addition, the complex nature of water radiolysis processes in liquid-cell experiments is beginning to be better understood, ${ }^{[25 c]}$ and this could 
lead to new methods for reducing the concentration of reactive radiolysis products, such as the addition of scavengers to remove radicals, thereby reducing beam-induced effects in all aqueous liquid-cell studies. ${ }^{[30]}$ Flowing liquid through the liquid-cell during imaging may also be beneficial in removing these reactive species and reducing beam damage. ${ }^{[16 a]}$ Ex situ studies can be used to complement liquid-cell investigations, ${ }^{[26 b, 30-31]}$ offering the potential for higher resolution imaging and analysis but with the disadvantage that the structures cannot be observed in their hydrated state. By performing HAADF STEM imaging and EDX spectrum imaging on Bio-PdAu in vacuum we can gain two important insights. First, we observe that many extremely small nanocrystals (typically $<3 \mathrm{~nm}$ in diameter) cover the surface of the cell, in addition to the larger nanocrystals with diameters above $\sim 20 \mathrm{~nm}$ observed in the liquid-cell investigation. Quantitative EDX analysis (SI Figure 5) revealed that the two populations of nanocrystals have different chemical compositions; the larger particles were palladium rich while the smaller particles contained a higher percentage of gold. Secondly, the larger particles have a core-shell structure with a Pd-rich shell typically only a few nanometers thick (Figure 5). This confirms the elemental segregation which was observed for the largest particles during in situ imaging (Figure 4c).

Theoretical studies using density functional theory (DFT) or classical molecular dynamics to study PdAu clusters suggest that Pd-core Au-shell structures are more energetically favourable than $\mathrm{Au}$-core Pd-shell or alloyed structures, due to strong Pd-Pd bonds and Au's lower surface energy. ${ }^{[32]}$ The fact that we observed the opposite segregation, suggests that kinetic rather than thermodynamic control is responsible for the core-shell structure. Aqueous solutions containing both $\mathrm{Au}(\mathrm{III})$ and $\mathrm{Pd}(\mathrm{II})$ have been reported to undergo reduction reactions to produce $\mathrm{Au}$-core $\mathrm{Pd}$-shell nanocrystals, with reduction performed by cetyltrimethylammonium bromide at $\sim 90{ }^{\circ} \mathrm{C},{ }^{[33]}$ or by sonochemical treatment at $20{ }^{\circ} \mathrm{C} .{ }^{[34]}$ Au-core Pd-shell structures can also be grown by deposition of Pd-shells on presynthesised 
Au seeds. ${ }^{[26 a]}$ The explanation of Pd-surface segregation in cases of simultaneous reduction likely lies in the reduction potentials of $\mathrm{Au}(\mathrm{III})$ and $\mathrm{Pd}(\mathrm{II})(+1.002 \mathrm{~V}$ and $+0.591 \mathrm{~V}$ respectively); in a case of slow reduction kinetics, $\mathrm{Au}(\mathrm{III})$ will be reduced in preference to Pd(II), initially forming Au seeds onto which Pd shells can subsequently grow. ${ }^{[33]}$ We believe that an analogous reaction mechanism is responsible for the core-shell structures observed in this work. This mechanism does not, however, account for the bimodal nanocrystal population consisting of small $\mathrm{Au}$ and larger PdAu nanocrystals. This may be explained by the fact that the reducing environment found on the bacterial outer membrane is considerably less homogeneous than that used in a typical solution-phase chemical synthesis of metal nanocrystals. The larger structures may reside at sites where electron transfer is especially favoured, perhaps due to a heterogeneous spatial distribution of $c$-type cytochromes on the outer membrane. ${ }^{[22 \mathrm{~b}, 23 \mathrm{a}]}$

The monometallic control samples display dramatically different crystal sizes, with the Au nanocrystals found in Bio-Au samples having a mean diameter of $16.7 \mathrm{~nm}$, while the Bio-Pd system contains particles with a mean diameter of $3.0 \mathrm{~nm}$ (SI Figure 6-8). Both monometallic systems are significantly morphologically different from the bimetallic system, although this is relatively unsurprising as one would expect additional redox processes to occur in the bimetallic system, for example galvanic replacement between $\mathrm{Au}(\mathrm{III})$ and $\mathrm{Pd}(0)$ species. $^{[35]}$

In a previous study of $\mathrm{PdAu}$ nanocrystals synthesised by the sulfate-reducing bacterium Desulfovibrio desulfuricans, ex situ EDX analysis found a mixture of homogeneously alloyed PdAu particles and nanocrystals displaying a Pd-core and an PdAu-shell. ${ }^{[10 \mathrm{c}]}$ However, as well as using a different Genus of bacteria lacking the battery of outer membrane c-type cytochromes noted in Geobacter species, ${ }^{[36]}$ this earlier study used a two-step synthesis where $\mathrm{Pd}(\mathrm{II})$ was reduced first, followed by reaction with $\mathrm{Au}(\mathrm{III}) .{ }^{[10 \mathrm{c}]} \mathrm{A}$ similar two-step reduction 
using Escherichia coli was found to produce Au-core Pd-shell structures. ${ }^{[2 \mathrm{c}]}$ It therefore appears that a range of different elemental segregation behaviours is accessible through the manipulation of biological nanocrystal synthesis processes. Furthermore, it is highly likely that systematically altering the concentration of metal salts would allow control of nanocrystal morphology, composition, and the extent of cell decoration.

The potential to control nanoscale elemental segregation is encouraging, however, the detailed mechanistic understanding that would allow rational design of synthesis by selection of an appropriate bacterial system and reaction conditions is still a long way from being realised. STEM spectrum imaging can play a critical role alongside synthetic biology approaches in developing this understanding. While widely used in studies of chemically synthesised nanocrystals, ${ }^{[8,37]}$ EDX spectrum imaging is currently rarely used to study bacterially synthesised nanocrystals. ${ }^{[10 \mathrm{c}]}$ Widespread adoption of the technique by the bionanocrystal synthesis research community would allow an understanding of the relationship between reaction conditions, nanoscale elemental distributions, microbial metabolism, and material performance during scalable biosynthesis for a wide range of applications. Furthermore, the ability to directly correlate liquid-cell electron microscopy with fluorescence microscopy opens up the possibility of identifying the active biomolecules involved in nanocrystal growth. It has previously been demonstrated that fluoresence microscopy of live yeast cells in a liquid-cell is possible prior to STEM imaging of the same structures. ${ }^{[18 \mathrm{~d}]}$ However, it should be noted that yeast cells are larger than Geobacter cells, hence attempts to map the distribution of biomolecules across individual microbes are likely to require super-resolution fluorescence techniques. ${ }^{[38]}$. 


\section{Conclusions}

Microbial synthesis offers a scalable and environmentally benign route to a range of functional nanomaterials, and in situ liquid-cell imaging and spectroscopy offers the potential to directly observe key reactive interfaces during nanomaterial synthesis. We have demonstrated, for the first time, the feasibility of performing EDX spectrum imaging on microbial structures in liquid. We performed HAADF STEM imaging and EDX spectrum imaging on PdAu nanocrystal decorated cells of Geobacter sulfurreducens, both in liquid and in vacuum. Liquid-cell experiments allowed us to observe the nanocrystal-decorated cells in their native hydrated state. The ability to perform EDX spectrum imaging in situ, allowed us to confirm that the nanostructures observed are PdAu and demonstrate co-localisation of the two elements across the entire cell. Complementary ex situ analysis in vacuum proved invaluable, with both HAADF STEM images and EDX spectrum imaging revealing nanoscale features that are below the spatial resolution of liquid-cell techniques, specifically a population of ultra-small gold-rich nanocrystals and a thin Pd-rich shell on the larger $\mathrm{PdAu}$ nanocrystals. Further work employing a combination of liquid-cell studies and highresolution ex situ analysis should yield significant insights into the mechanisms underpinning bacterial nanocrystal synthesis, leading to improved control of size, shape, elemental segregation, and, ultimately, material (e.g. catalytic) performance. More generally, the ability to perform nanoscale elemental mapping on hydrated biological specimens, should allow mechanistic insights into important processes at the biological-inorganic interface such as during biomineralisation, ${ }^{[39]}$ nanoparticle uptake by cells, ${ }^{[18 b]}$ and the formation and function of bio-nanoparticles, including catalysts, ${ }^{[6]}$ quantum dots, ${ }^{[40]}$ and nano-scale magnetic particles. ${ }^{[2 \mathrm{~b}]}$ Widespread application of these techniques could also help underpin significant advances in our understanding of nanoscale geomicrobiological processes that are mediated at the bio-geo interface and have major impacts to natural and engineered environments, 
often with global implications. We hope that this study provides an important step towards direct observation of bacterial nanocrystal synthesis in vivo.

\section{Experimental section}

\section{Bacteria culture:}

Geobacter sulfurreducens was cultured anaerobically to late log phase $\left(\mathrm{OD}_{600}=0.61\right)$ at $30{ }^{\circ} \mathrm{C}$ in $50 \mathrm{ml}$ of a modified freshwater enrichment medium, with $40 \mathrm{mM}$ fumarate as an electron acceptor and $25 \mathrm{mM}$ acetate as an electron donor. ${ }^{[41]}$ The growth medium was then washed from the cells by centrifugation for 20 minutes at $1800 \mathrm{~g}$ and the cells were resuspended in $30 \mathrm{mM} \mathrm{NaHCO}$, washed again by centrifugation and resuspended in $10 \mathrm{ml}$ fresh $30 \mathrm{mM} \mathrm{NaHCO}$.

\section{Nanoparticle growth:}

The bacteria were used to generate bimetallic PdAu nanoparticles by simultaneous reaction with $\mathrm{Au}(\mathrm{III})$ and $\mathrm{Pd}(\mathrm{II}) .2 \mathrm{ml}$ of the Geobacter sulfurreducens cell suspension was added to a $6 \mathrm{ml}$ anaerobic solution of $1 \mathrm{mM} \mathrm{Au}(\mathrm{III}) \mathrm{Cl}_{3}$ and $1 \mathrm{mM} \mathrm{Na}_{2} \mathrm{Pd}(\mathrm{II}) \mathrm{Cl}_{4}$ in $\mathrm{dH}_{2} \mathrm{O}$. The solution was mixed gently, and then sparged with $\mathrm{H}_{2}$ gas (as the electron donor for metal reduction) for 1 minute. The solution changed colour from pale, transparent yellow to opaque grey/black shortly after adding the $\mathrm{H}_{2}$. Control samples were also set up under the following conditions. Control 1) $\mathrm{Au}(\mathrm{III})$ only: $6 \mathrm{ml}$ anaerobic solution of $2 \mathrm{mM} \mathrm{Au}(\mathrm{III}) \mathrm{Cl}_{3}$ in $\mathrm{dH}_{2} \mathrm{O}, 2 \mathrm{ml}$ cell suspension added, sparged with $\mathrm{H}_{2}$ for 1 minute. Control 2) Pd(II) only: $6 \mathrm{ml}$ anaerobic solution of $2 \mathrm{mM} \mathrm{Na} 2 \mathrm{Pd}(\mathrm{II}) \mathrm{Cl}_{4}$ in $\mathrm{dH}_{2} \mathrm{O}, 2 \mathrm{ml}$ cell suspension added, sparged with $\mathrm{H}_{2}$ for 1 minute. Control 3) No electron donor: $6 \mathrm{ml}$ anaerobic solution of $1 \mathrm{mM} \mathrm{Au(III)Cl} \mathrm{C}_{3}$ and $1 \mathrm{mM}$ $\mathrm{Na}_{2} \mathrm{Pd}(\mathrm{II}) \mathrm{Cl}_{4}$ in $\mathrm{dH}_{2} \mathrm{O}, 2 \mathrm{ml}$ cell suspension added but not sparged with $\mathrm{H}_{2}$. 


\section{Liquid-cell assembly:}

Liquid-cell chips were purchased from Protochips Inc. Chips designed for flow experiments were used with $500 \mathrm{~nm}$ gold spacers at the corners of the lower chip. Chips were cleaned by immersion in acetone and then methanol. The chips were dried and then cleaned in a Hitachi Zone SEM UV cleaner, which was operated in vacuum clean mode for 10 minutes to remove surface hydrocarbon contamination and create a hydrophilic surface. The smaller lower chip was set aside while the larger upper chip was immersed in $0.01 \%$ Poly-L-lysine solution for 5 minutes and then allowed to dry. A Protochips Poseidon 200 liquid-cell TEM holder was cleaned by flowing DI water through all lines. Two greased O-rings and the lower chip were fitted into the tip of the holder. $10 \mu \mathrm{L}$ of Bio-PdAususpension was dropped onto the upper chip which was then loaded into the holder, trapping a layer of the cell suspension between the two chips. The chips were loaded so that the two rectangular windows formed a cross, giving a small square viewing window, this geometry gives less window bowing but a smaller viewing area. ${ }^{[20 \mathrm{a}]}$ The liquid-cell was then sealed by screwing down a modified top plate specifically designed to reduce shadowing of X-rays and described in our previous work. ${ }^{[21]}$ The quality of seal was assessed by pumping the holder in a Pfeiffer HiCube Eco turbomolecular pumping station. The rate of pressure change during pumping in this station has been calibrated against previous liquid-cell experiments, so we can be confident that the windows are intact and no pinholes or other small leaks are present. To remove unreacted $\mathrm{Au}(\mathrm{III})$ and $\mathrm{Pd}(\mathrm{II})$ salts from the liquid-cell, a solution of $30 \mathrm{mM} \mathrm{NaHCO} \mathrm{N}_{3}$ was flowed through the holder at a rate of $300 \mu \mathrm{L} /$ hour for 60 minutes. The holder lines were then plugged and the holder loaded into the STEM.

\section{Ex situ sample preparation:}

For high resolution imaging and spectrum imaging in vacuum samples were subjected to a solution phase cleaning procedure. $2 \mathrm{ml}$ of acetone was added to $8 \mathrm{ml}$ of nanoparticle/bacteria 
suspension, the suspension was centrifuged at $1540 \mathrm{~g}$ for 10 minutes to form a pellet and the supernatant was discarded. The pellet was resuspended in $4 \mathrm{ml}$ of a 50:50 chloroform: methanol mixture and sonicated in an ultrasonic bath for 20 minutes. The resulting suspension was then centrifuged at $1540 \mathrm{~g}$ for 10 minutes to form a pellet and the supernatant was discarded. The pellet was resuspended in $6 \mathrm{ml}$ of $\mathrm{dH}_{2} \mathrm{O}$. The resulting suspension was then drop cast onto holey carbon TEM grids and allowed to dry.

\section{Scanning transmission electron microscopy:}

HAADF STEM images and EDX spectrum images were acquired using a probe-side aberration corrected FEI Titan G2 80-200 S/TEM “ChemiSTEM"M" instrument equipped with the Super-X four silicon drift detector (SDD) system and operated at $200 \mathrm{kV}$. Images and spectrum images were acquired with a probe current of $\sim 200 \mathrm{pA}$ and a convergence semi-angle of 18.5 mrad. HAADF imaging was performed with an inner collection semiangle of $54 \mathrm{mrad}$. For liquid-cell experiments the Poseidon holder was tilted $30^{\circ}$ and only two of the four SDDs employed in order to reduce detector shadowing from the sides of the specimen holder as described in reference 21a. ${ }^{[21 \mathrm{a}]}$ EDX spectrum images for the specimen in vacuum were acquired using the FEI low background double-tilt holder with all four SSD detectors turned on and the sample un-tilted. EDX data was acquired and processed using Bruker Esprit software. Quantification was performed using the Cliff-Lorimer approach without absorption correction. STEM images were acquired using FEI TIA software and processed using the Image-J software.

\section{Cryo TEM:}

To prepare the samples for Cryo-TEM, $3 \mu 1$ of fresh bacteria/nanoparticle suspension (prepared as described for nanoparticle growth) was added to freshly glow-discharged gold 300 mesh holey carbon coated grids (Elektron Technology) or Quantifoil R2/2 grids. Grids were blotted continuously for 4-8 seconds using a Vitrobot at $95 \%$ humidity and the grids 
were then plunge frozen immediately into ethane. Data were recorded using a FEI Tecnai 30 Polara G2 FEG with a Gatan Ultrascan 4K CCD operating in low dose imaging mode images were recorded at a calibrated $18,000 \times$ magnification at $300 \mathrm{kV}$.

For all liquid-cell, ex situ, and cryo electron microscopy experiments presented in this work no staining techniques were used on the microbes.

\section{Acknowledgements}

E.A.L. is funded by an Engineering and Physical Sciences Research Council (EPSRC) doctoral prize fellowship, grant number EP/M506436/1. S.J.H. thanks the Defence Threat Reduction Agency for funding support, grant HDTRA1-12-1-0013, and EPSRC grants EP/K016946/1 and EP/G03737X/1. J. R.L would acknowledges NERC NIMMI grant number NE/J024732/1.

[1] a)J. R. Lloyd, J. M. Byrne, V. S. Coker, Curr. Opin. Biotech. 2011, 22, 509-515; b)L. E. Macaskie, I. P. Mikheenko, P. Yong, K. Deplanche, A. J. Murray, M. PatersonBeedle, V. S. Coker, C. I. Pearce, R. Cutting, R. A. D. Pattrick, D. Vaughan, G. van der Laan, J. R. Lloyd, Hydrometallurgy 2010, 104, 483-487; c)K. B. Narayanan, N. Sakthivel, Adv. Colloid Interfac. 2010, 156, 1-13.

[2] a) M. Kowshik, W. Vogel, J. Urban, S. K. Kulkarni, K. M. Paknikar, Adv. Mater. 2002, 14, 815-818; b)V. S. Coker, J. A. Bennett, N. D. Telling, T. Henkel, J. M. Charnock, G. van der Laan, R. A. D. Pattrick, C. I. Pearce, R. S. Cutting, I. J. Shannon, J. Wood, E. Arenholz, I. C. Lyon, J. R. Lloyd, ACS Nano 2010, 4, $2577-$ 2584; c)K. Deplanche, M. L. Merroun, M. Casadesus, D. T. Tran, I. P. Mikheenko, J. A. Bennett, J. Zhu, I. P. Jones, G. A. Attard, J. Wood, S. Selenska-Pobell, L. E. Macaskie, J. R. Soc. Interface 2012, 9, 1705-1712.

[3] a)G. Reguera, K. D. McCarthy, T. Mehta, J. S. Nicoll, M. T. Tuominen, D. R. Lovley, Nature 2005, 435, 1098-1101; b)L. Shi, D. J. Richardson, Z. Wang, S. N. Kerisit, K. M. Rosso, J. M. Zachara, J. K. Fredrickson, Environ. Microbiol. Rep. 2009, 1, 220227. 
[4] a)M. D. Yates, R. D. Cusick, B. E. Logan, ACS Sustainable Chem. Eng. 2013, 1, 1165-1171; b)N. Law, S. Ansari, F. R. Livens, J. C. Renshaw, J. R. Lloyd, Appl. Environ. Microbiol. 2008, 74, 7090-7093.

[5] a)J. M. Byrne, V. S. Coker, E. Cespedes, P. L. Wincott, D. J. Vaughan, R. A. D. Pattrick, G. van der Laan, E. Arenholz, F. Tuna, M. Bencsik, J. R. Lloyd, N. D.

Telling, Adv. Funct. Mater. 2014, 24, 2518-2529; b)J. M. Byrne, H. Muhamadali, V. S. Coker, J. Cooper, J. R. Lloyd, Scale-up of the production of highly reactive biogenic magnetite nanoparticles using Geobacter sulfurreducens, Vol. 12, 2015; c)J. M. Byrne, N. D. Telling, V. S. Coker, R. A. D. Pattrick, G. v. d. Laan, E. Arenholz, F. Tuna, J. R. Lloyd, Nanotechnology 2011, 22, 455709.

[6] S. De Corte, T. Hennebel, J. P. Fitts, T. Sabbe, V. Bliznuk, S. Verschuere, D. van der Lelie, W. Verstraete, N. Boon, Environ Sci. Technol. 2011, 45, 8506-8513.

[7] a)N. Toshima, T. Yonezawa, New J. Chem. 1998, 22, 1179-1201; b)M. Sankar, N. Dimitratos, P. J. Miedziak, P. P. Wells, C. J. Kiely, G. J. Hutchings, Chem. Soc. Rev. 2012, 41, 8099-8139.

[8] T. J. A. Slater, A. Macedo, S. L. M. Schroeder, M. G. Burke, P. O’Brien, P. H. C. Camargo, S. J. Haigh, Nano Lett. 2014, 14, 1921-1926.

[9] a)W. Zhou, J. Y. Lee, Electrochem. Commun. 2007, 9, 1725-1729; b)M. Hosseini, S. Siffert, H. L. Tidahy, R. Cousin, J. F. Lamonier, A. Aboukais, A. Vantomme, M. Roussel, B. L. Su, Catal. Today 2007, 122, 391-396; c)M. O. Nutt, K. N. Heck, P. Alvarez, M. S. Wong, Appl. Catal. B 2006, 69, 115-125; d)D. I. Enache, J. K. Edwards, P. Landon, B. Solsona-Espriu, A. F. Carley, A. A. Herzing, M. Watanabe, C. J. Kiely, D. W. Knight, G. J. Hutchings, Science 2006, 311, 362-365; e)A. G. M. da Silva, H. V. Fajardo, R. Balzer, L. F. D. Probst, A. S. P. Lovón, J. J. LovónQuintana, G. P. Valença, W. H. Schreine, P. A. Robles-Dutenhefner, J. Power Sources 2015, 285, 460-468.

[10] a)T. S. A. Heugebaert, S. De Corte, T. Sabbe, T. Hennebel, W. Verstraete, N. Boon, C. V. Stevens, Tetrahedron Lett. 2012, 53, 1410-1412; b)B. Hosseinkhani, L. S. Søbjerg, A.-E. Rotaru, G. Emtiazi, T. Skrydstrup, R. L. Meyer, Biotechnol. Bioeng. 2012, 109, 45-52; c)D. T. Tran, I. P. Jones, J. A. Preece, R. L. Johnston, K. Deplanche, L. E. Macaskie, Nanotechnology 2012, 23, 055701.

[11] M. C. Edmundson, M. Capeness, L. Horsfall, New Biotechnol. 2014, 31, 572-578.

[12] a)M. Aklujkar, M. V. Coppi, C. Leang, B. C. Kim, M. A. Chavan, L. A. Perpetua, L. Giloteaux, A. Liu, D. E. Holmes, Microbiology 2013, 159, 515-535; b)Y. Yang, Y. Ding, Y. Hu, B. Cao, S. A. Rice, S. Kjelleberg, H. Song, ACS Synth. Biol. 2015, 4, 815-823; c)X. Jiang, J. Hu, A. M. Lieber, C. S. Jackan, J. C. Biffinger, L. A. Fitzgerald, B. R. Ringeisen, C. M. Lieber, Nano Lett. 2014, 11, 6737-6742.

[13] H. L. Xin, J. A. Mundy, Z. Liu, R. Cabezas, R. Hovden, L. F. Kourkoutis, J. Zhang, N. P. Subramanian, R. Makharia, F. T. Wagner, D. A. Muller, Nano Lett. 2012, 12, 490-497.

[14] a)M. J. Williamson, R. M. Tromp, P. M. Vereecken, R. Hull, F. M. Ross, Nat. Mater. 2003, 2, 532-536; b)N. de Jonge, F. M. Ross, Nat. Nanotechnol. 2011, 6, 695-704; c)F. M. Ross, Science 2015, 350, 6267.

[15] a)H. G. Liao, L. K. Cui, S. Whitelam, H. M. Zheng, Science 2012, 336, 1011-1014; b)H. G. Liao, K. Niu, H. Zheng, Chem. Commun. 2013, 49, 11720-11727; c)H. Zheng, R. K. Smith, Y.-w. Jun, C. Kisielowski, U. Dahmen, A. P. Alivisatos, Science 2009, 324, 1309-1312; d)J. P. Patterson, P. Abellan, M. S. Denny, C. Park, N. D. Browning, S. M. Cohen, J. E. Evans, N. C. Gianneschi, J. Am. Chem. Soc. 2015, 137, $7322-7328$. 
[16] a)N. de Jonge, D. B. Peckys, G. J. Kremers, D. W. Piston, Proc. Natl. Acad. Sci. U.S.A. 2009, 106, 2159-2164; b)N. de Jonge, N. Poirier-Demers, H. Demers, D. B. Peckys, D. Drouin, Ultramicroscopy 2010, 110, 1114-1119; c)M. J. Dukes, D. B. Peckys, N. de Jonge, ACS Nano 2010, 4, 4110-4116.

[17] E. S. Pohlmann, K. Patel, S. Guo, M. J. Dukes, Z. Sheng, D. F. Kelly, Nano Lett. 2015, 15, 2329-2335.

[18] a)E. A. Ring, D. B. Peckys, M. J. Dukes, J. P. Baudoin, N. De Jonge, J. Microsc. 2011, 243, 273-283; b)D. B. Peckys, N. de Jonge, Nano Lett. 2011, 11, 1733-1738; c)D. B. Peckys, N. de Jonge, Microsc. Microanal. 2014, 20, 346-365; d)D. B. Peckys, P. Mazur, K. L. Gould, N. de Jonge, Biophys. J. 2011, 100, 2522-2529.

[19] a)D. B. Peckys, G. M. Veith, D. C. Joy, N. de Jonge, PLoS ONE 2009, 4, e8214; b)T. J. Woehl, S. Kashyap, E. Firlar, T. Perez-Gonzalez, D. Faivre, D. Trubitsyn, D. A. Bazylinski, T. Prozorov, Sci. Rep. 2014, 4, 6854.

[20] a)M. E. Holtz, Y. Yu, J. Gao, H. D. Abruna, D. A. Muller, Microsc. Microanal. 2013, 19, 1027-1035; b)M. E. Holtz, Y. Yu, D. Gunceler, J. Gao, R. Sundararaman, K. A. Schwarz, T. A. Arias, H. D. Abruña, D. A. Muller, Nano Lett. 2014, 14, 1453-1459; c)K. L. Jungjohann, J. E. Evans, J. A. Aguiar, I. Arslan, N. D. Browning, Microsc. Microanal. 2012, 18, 621-627; d)A. J. Leenheer, K. L. Jungjohann, K. R. Zavadil, J. P. Sullivan, C. T. Harris, ACS Nano 2015, 9, 4379-4389; e)R. R. Unocic, L. Baggetto, G. M. Veith, J. A. Aguiar, K. A. Unocic, R. L. Sacci, N. J. Dudney, K. L. More, Chem. Commun. 2015.

[21] a)E. A. Lewis, S. J. Haigh, T. J. A. Slater, Z. He, M. A. Kulzick, M. G. Burke, N. J. Zaluzec, Chem. Commun. 2014, 50, 10019-10022; b)N. J. Zaluzec, M. G. Burke, S. J. Haigh, M. A. Kulzick, Microsc. Microanal. 2014, 20, 323-329.

[22] a)L. Shi, T. C. Squier, J. M. Zachara, J. K. Fredrickson, Mol. Microbiol. 2007, 65, 1220; b)M. J. Marshall, A. S. Beliaev, A. C. Dohnalkova, D. W. Kennedy, L. Shi, Z. Wang, M. I. Boyanov, B. Lai, K. M. Kemner, J. S. McLean, Plos Biol. 2006, 4(8), 268.

[23] a)R. Orellana, J. J. Leavitt, L. R. Comolli, R. Csencsits, N. Janot, K. A. Flanagan, A. S. Gray, C. Leang, M. Izallalen, T. Mester, Appl. Environ. Microbiol. 2013, 79, 63696374; b)T. Mehta, M. V. Coppi, S. E. Childers, D. R. Lovley, Appl. Environ. Microbiol. 2005, 71, 8634-8641.

[24] C. Ha, N. Zhu, R. Shang, C. Shi, J. Cui, I. Sohoo, P. Wu, Y. Cao, Chem. Eng. J. 2016, 288, 246-254.

[25] a)H. Zheng, U. M. Mirsaidov, L.-W. Wang, P. Matsudaira, Nano Lett. 2012, 12 , 5644-5648; b)Y. Z. Liu, X. M. Lin, Y. G. Sun, T. Rajh, J. Am. Chem. Soc. 2013, 135, 3764-3767; c)N. M. Schneider, M. M. Norton, B. J. Mendel, J. M. Grogan, F. M. Ross, H. H. Bau, J. Phys. Chem. C 2014, 118, 22373-22382.

[26] a)K. L. Jungjohann, S. Bliznakov, P. W. Sutter, E. A. Stach, E. A. Sutter, Nano Lett. 2013, 13, 2964-2970; b)D. Alloyeau, W. Dachraoui, Y. Javed, H. Belkahla, G. Wang, H. Lecoq, S. Ammar, O. Ersen, A. Wisnet, F. Gazeau, C. Ricolleau, Nano Lett. 2015, $15,2574-2581$.

[27] T. J. Woehl, K. L. Jungjohann, J. E. Evans, I. Arslan, W. D. Ristenpart, N. D. Browning, Ultramicroscopy 2013, 127, 53-63.

[28] J. Park, H. Elmlund, P. Ercius, J. M. Yuk, D. T. Limmer, Q. Chen, K. Kim, S. H. Han, D. A. Weitz, A. Zettl, A. P. Alivisatos, Science 2015, 349, 290-295.

[29] N. J. Zaluzec, Microsc. Today 2009, 17, 56-59.

[30] E. Sutter, K. Jungjohann, S. Bliznakov, A. Courty, E. Maisonhaute, S. Tenney, P. Sutter, Nat. Commun. 2014, 5, 4946. 
[31] J. Wu, W. Gao, J. Wen, D. J. Miller, P. Lu, J.-M. Zuo, H. Yang, Nano Lett. 2015, 15, 2711-2715.

[32] a)F. Pittaway, L. O. Paz-Borbón, R. L. Johnston, H. Arslan, R. Ferrando, C. Mottet, G. Barcaro, A. Fortunelli, J. Phys. Chem. C 2009, 113, 9141-9152; b)H. B. Liu, U. Pal, R. Perez, J. A. Ascencio, J. Phys. Chem. B 2006, 110, 5191-5195.

[33] Y. W. Lee, M. Kim, Z. H. Kim, S. W. Han, J. Am. Chem. Soc. 2009, 131, 1703617037.

[34] Y. Mizukoshi, T. Fujimoto, Y. Nagata, R. Oshima, Y. Maeda, J. Phys. Chem. B 2000, 104, 6028-6032.

[35] a)X. Teng, Q. Wang, P. Liu, W. Han, A. I. Frenkel, Wen, N. Marinkovic, J. C. Hanson, J. A. Rodriguez, J. Am. Chem. Soc. 2008, 130, 1093-1101; b)X. Xia, Y. Wang, A. Ruditskiy, Y. Xia, Adv. Mater. 2013, 25, 6313-6333.

[36] E. S. Shelobolina, M. V. Coppi, A. A. Korenevsky, L. N. DiDonato, S. A. Sullivan, H. Konishi, H. Xu, C. Leang, J. E. Butler, B.-C. Kim, BMC microbiol. 2007, 7, 16.

[37] a)E. A. Lewis, T. J. A. Slater, E. Prestat, A. Macedo, P. O'Brien, P. H. C. Camargo, S. J. Haigh, Nanoscale 2014, 6, 13598-13605; b)D. J. Lewis, A. A. Tedstone, X. L. Zhong, E. A. Lewis, A. Rooney, N. Savjani, J. R. Brent, S. J. Haigh, M. G. Burke, C. A. Muryn, J. M. Raftery, C. Warrens, K. West, S. Gaemers, P. O’Brien, Chem. Mater. 2015, 27, 1367-1374; c)A. G. M. Da Silva, E. A. Lewis, T. S. Rodrigues, T. J. A. Slater, R. S. Alves, S. J. Haigh, P. H. C. Camargo, Chem. Eur. J. 2015, 21, 1231412320; d)A. G. M. da Silva, T. S. Rodrigues, T. J. A. Slater, E. A. Lewis, R. S. Alves, H. V. Fajardo, R. Balzer, A. H. M. da Silva, I. C. de Freitas, D. C. Oliveira, J. M. Assaf, L. F. D. Probst, S. J. Haigh, P. H. C. Camargo, ACS Appl. Mater. Interfaces 2015, 7, 25624-25632.

[38] a)M. Fernandez-Suarez, A. Y. Ting, Nat. Rev. Mol. Cell Biol. 2008, 9, 929-943; b)J. S. Biteen, M. A. Thompson, N. K. Tselentis, G. R. Bowman, L. Shapiro, W. E. Moerner, Nat. Meth. 2008, 5, 947-949.

[39] a)P. J. M. Smeets, K. R. Cho, R. G. E. Kempen, N. A. J. M. Sommerdijk, J. J. De Yoreo, Nat. Mater. 2015, 14, 394-399; b)R. Kroger, Nat. Mater. 2015, 14, 369-370.

[40] a)S. R. Sturzenbaum, HocknerM, PanneerselvamA, LevittJ, J. S. Bouillard, TaniguchiS, L. A. Dailey, R. A. Khanbeigi, E. V. Rosca, ThanouM, SuhlingK, A. V. Zayats, GreenM, Nat. Nano. 2013, 8, 57-60; b) M. Green, S. J. Haigh, E. A. Lewis, L. Sandiford, M. Burkitt-Gray, R. Fleck, G. Vizcay-Barrena, L. Jensen, H. Mirzai, R. J. Curry, L. A. Dailey, Sci. Rep. 2016, 6, 20480.

[41] D. R. Lovley, E. J. P. Phillips, Appl. Environ. Microbiol. 1988, 54, 1472-1480. 

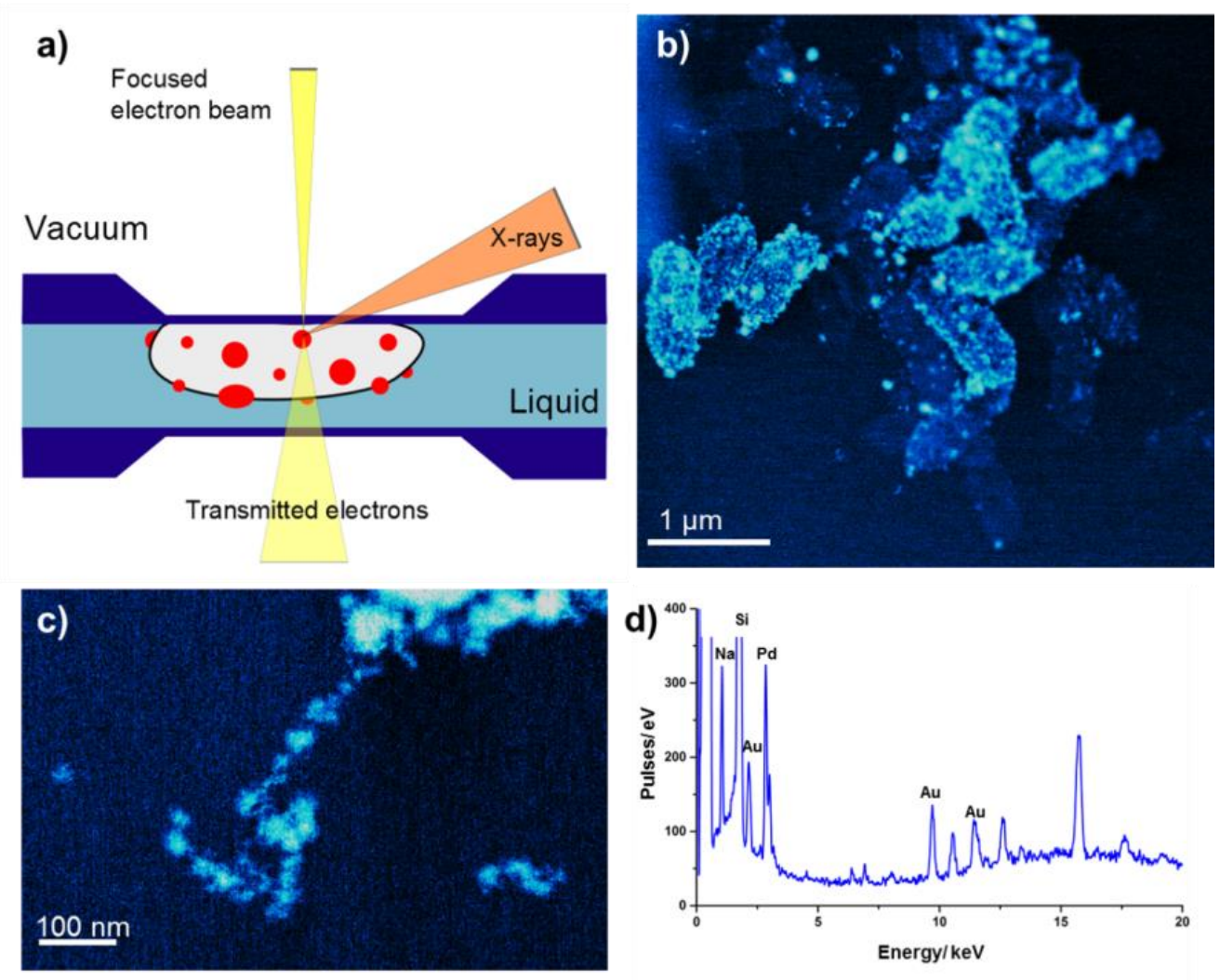

Figure 1. (a) Schematic of experimental setup. (b) Typical HAADF STEM images showing a mixture of bare and PdAu decorated hydrated cells of Geobacter sulfurreducens. (c) HAADF STEM image showing an extracellular chain of nanocrystals. (d) EDX spectrum from a hydrated cell, clearly confirming the presence of Au and Pd. HAADF images are false colored using a blue scale to improve clarity. 
a)
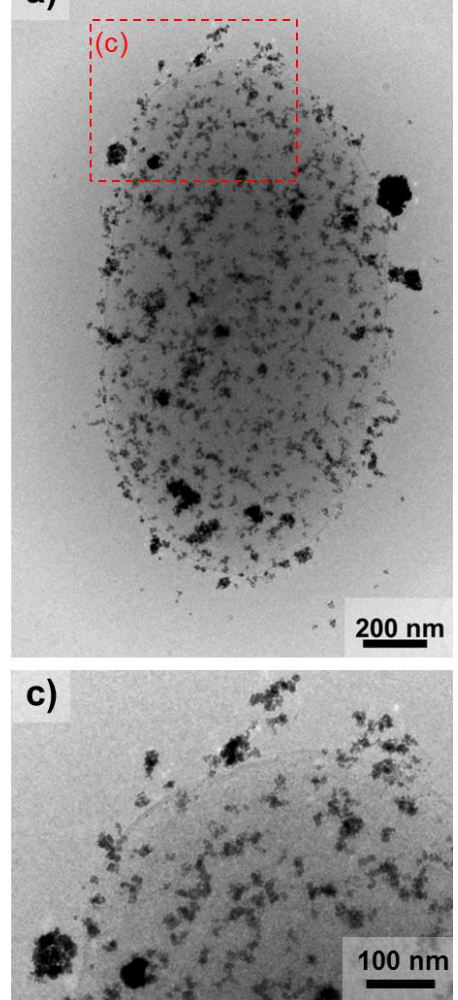

b)
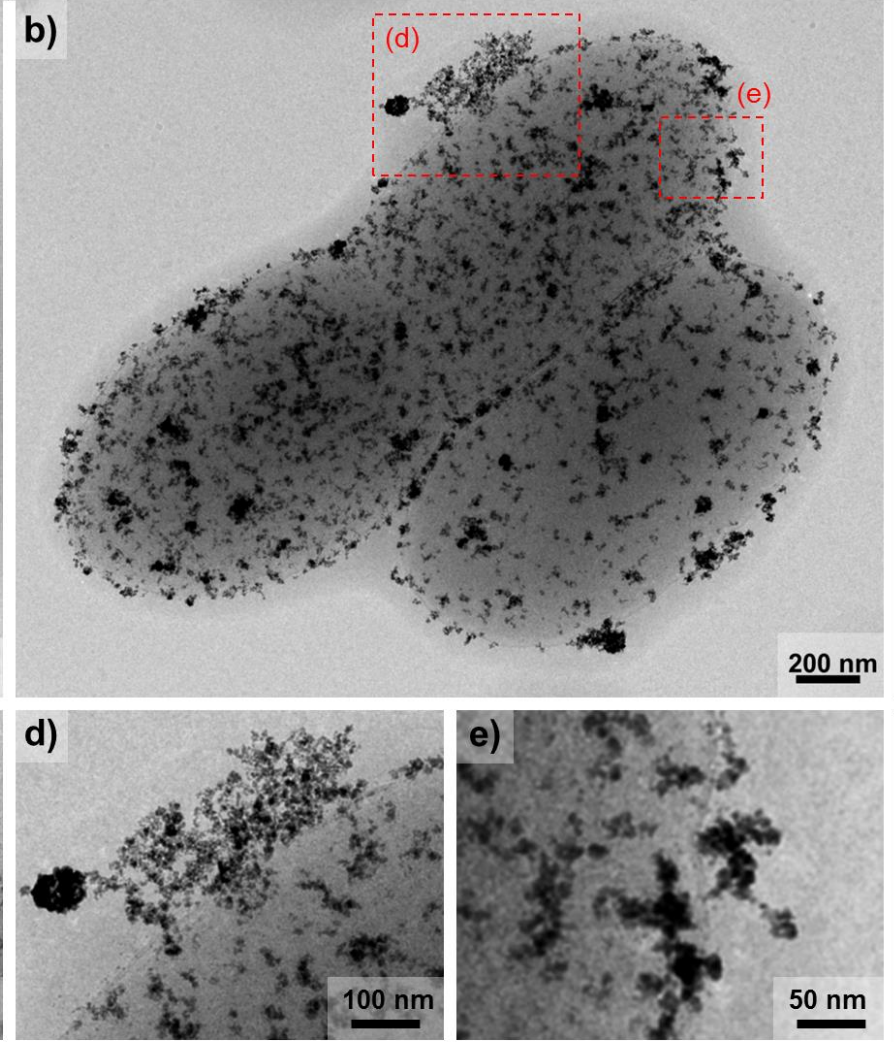

Figure 2. Cryo-TEM images of Bio-PdAu, (a) and (b) show images of whole bacteria, while (c-e) show magnified regions indicated by the dashed boxes in (a) and (b). 

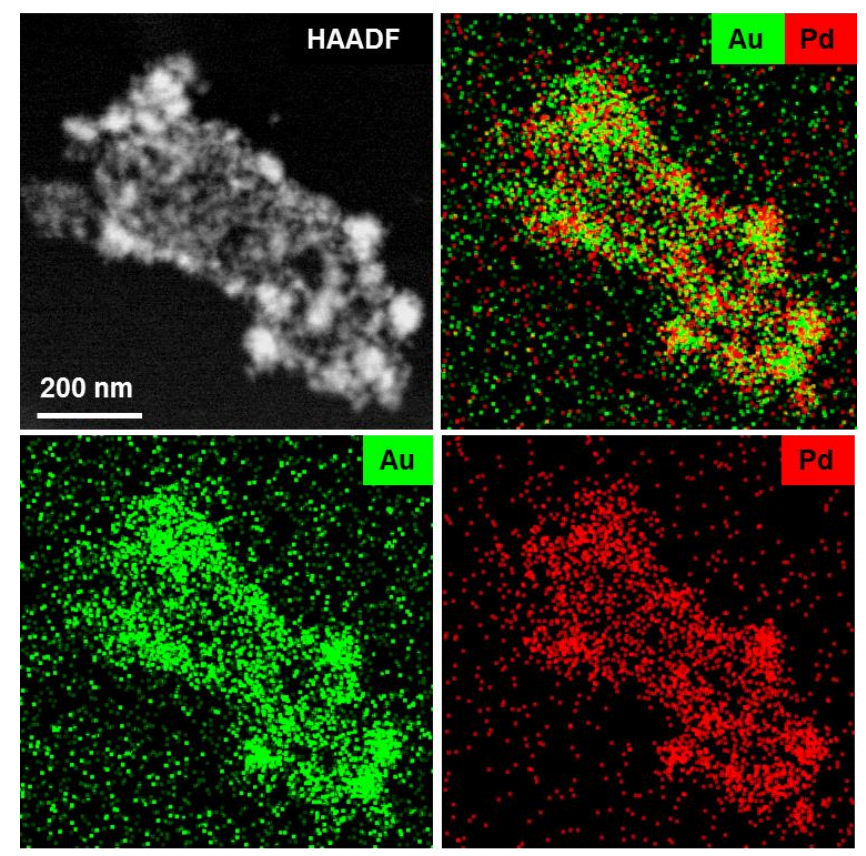

Figure 3. HAADF STEM image and EDX spectrum image of a single hydrated bacterium. Elemental maps (based on $\mathrm{Au} \mathrm{L}_{\alpha}$ and $\mathrm{M}_{\alpha}$ counts and $\mathrm{Pd} \mathrm{L}_{\alpha}$ counts) show clear co-localisation of $\mathrm{Au}$ and $\mathrm{Pd}$ across the entire cell. The corresponding EDX spectrum can be found in SI Figure S3.
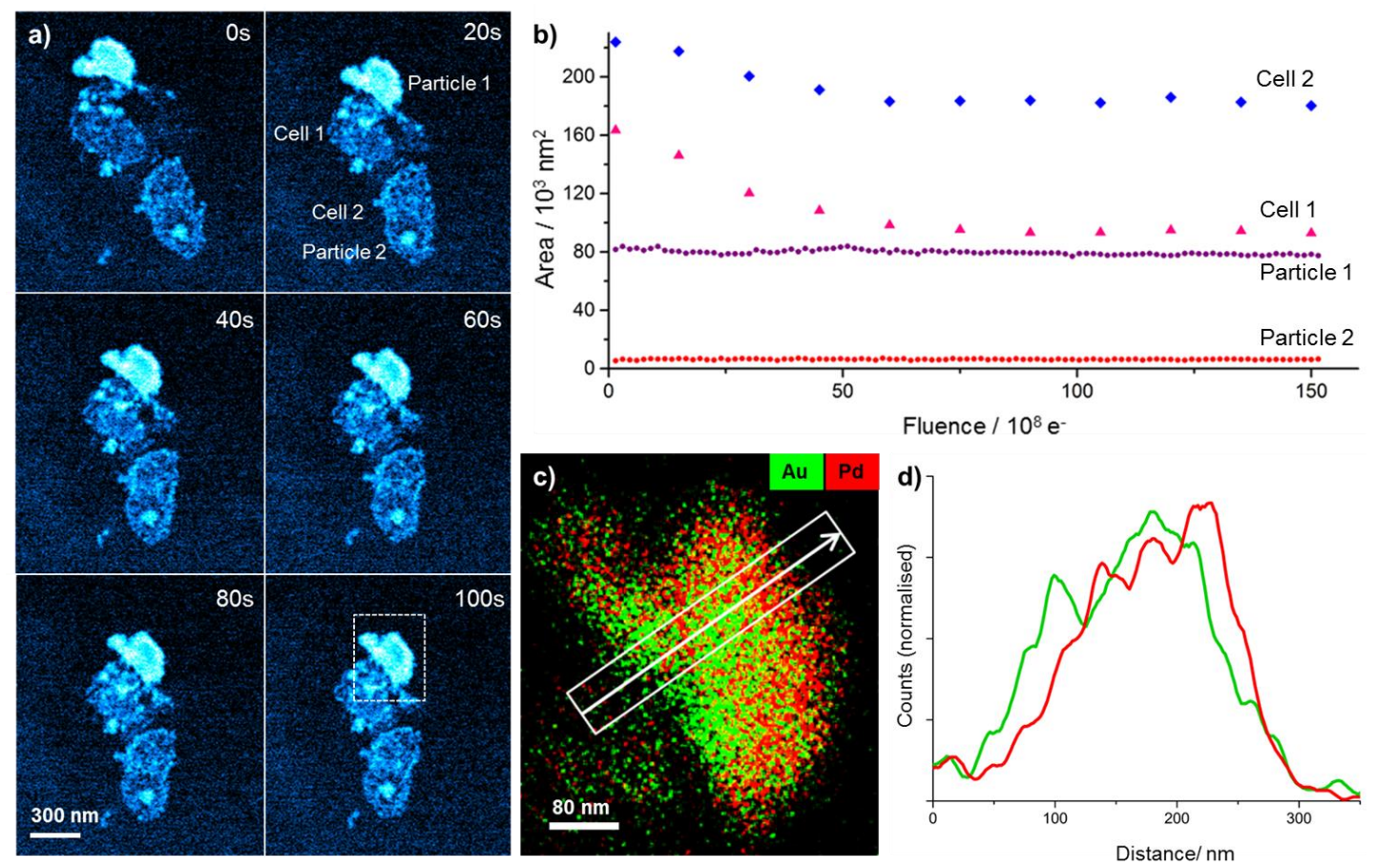

Figure 4. (a) Beam induced motion and shrinkage of a structure comprising two cells, one bearing an unusually large nanocrystal. (b) Beam induced shrinkage of features in (a), inorganic nanocrystals are stable while cells initially shrink before reaching a stable reduced size. (c) EDX spectrum image of the large nanocrystal indicated by the box in the bottom 
right panel of (a), a line-scan (d) demonstrates elemental segregation. Summed EDX spectrum and individual elemental maps can be found in SI Figure S4.
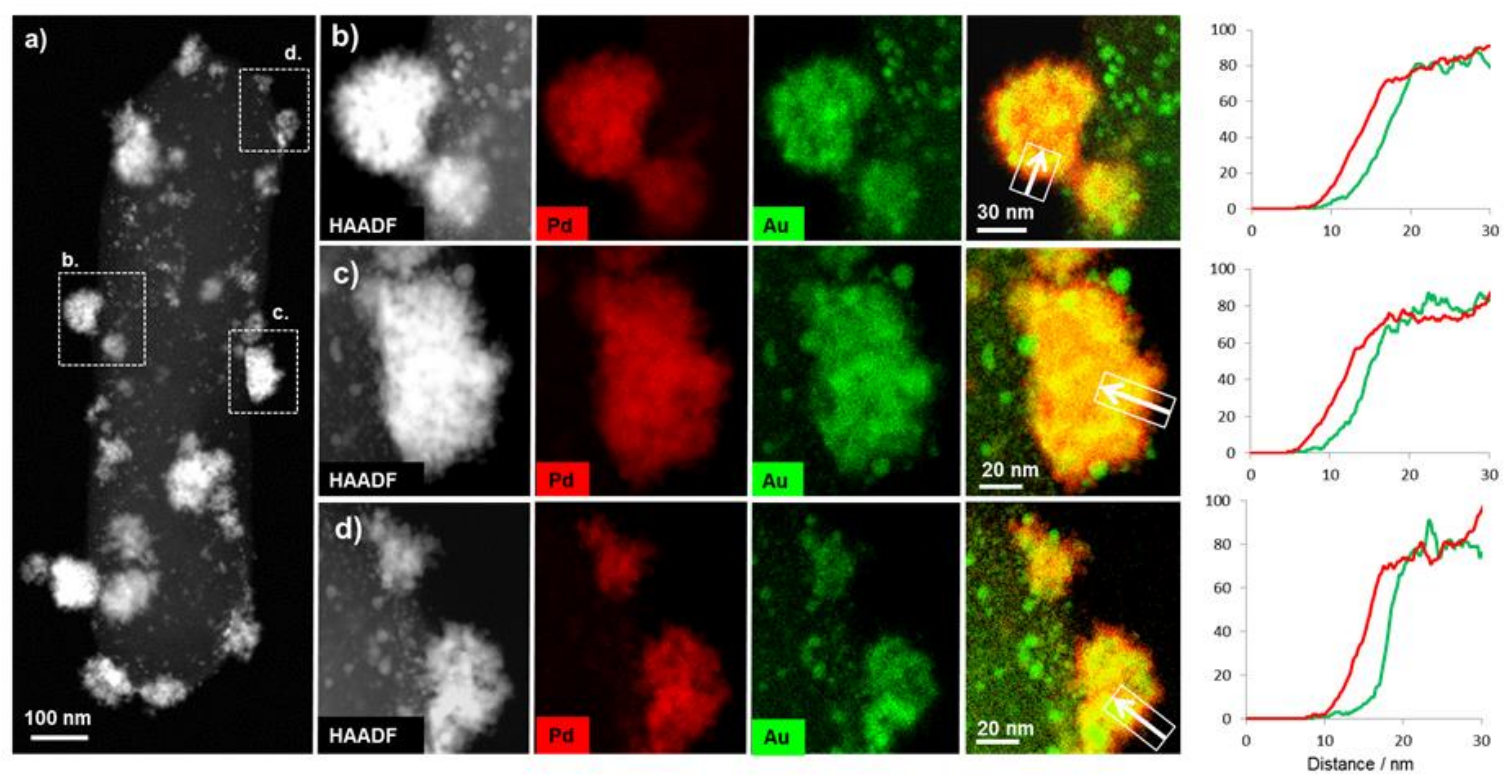

Figure 5. Ex situ HAADF STEM images and EDX spectrum images of a PdAu decorated Geobacter sulfurreducens cell in vacuum. (a) shows a low magnification image of the entire cell, with regions (b-d) indicated. Spectrum images and lines scans of these regions (b-d) are shown, in all cases demonstrating a Pd-rich shell on the larger particles. 